Research Article

\title{
Comparison of Dynamic Responses of Parallel-Placed Adjacent High-Rise Buildings under Wind and Earthquake Excitations
}

\author{
Huaxiao Wu $\mathbb{D}^{1}{ }^{1}$ Qinhua Wang ${ }^{(D)}{ }^{2}$ Nayan Deep Tiwari $\mathbb{D}^{1},{ }^{1}$ and Dario De Domenico ${ }^{3}{ }^{3}$ \\ ${ }^{1}$ Department of Civil and Environmental Engineering, Shantou University, Shantou 515063, China \\ ${ }^{2}$ School of Civil Engineering and Architecture, Southwest University of Science and Technology, Mianyang 621010, China \\ ${ }^{3}$ Department of Engineering, University of Messina, Messina 98166, Italy
}

Correspondence should be addressed to Qinhua Wang; qinhuawang@stu.edu.cn

Received 4 November 2020; Revised 3 May 2021; Accepted 12 June 2021; Published 28 June 2021

Academic Editor: Salvatore Caddemi

Copyright $\odot 2021$ Huaxiao Wu et al. This is an open access article distributed under the Creative Commons Attribution License, which permits unrestricted use, distribution, and reproduction in any medium, provided the original work is properly cited.

Two parallel-placed adjacent high-rise buildings are often linked to each other through passive control devices for vibration mitigation purposes. The mitigation efficiency of these control devices mainly depends on the characteristics of relative dynamic responses, namely, opposite-sign and same-sign responses of the two buildings. The present research first identifies an oppositesign response factor to estimate the time ratio of opposite-sign responses. Subsequently, a structure comprising two adjacent highrise buildings (with different natural frequency ratios) subjected to both wind and earthquake excitations is analyzed. Windinduced responses are evaluated based on wind loads obtained from wind tunnel tests, while earthquake responses are determined through a suite of 44 natural ground-motion records. The results indicate that opposite-sign factors of the displacement, velocity, and acceleration responses under wind loads, especially at across-wind direction, are larger than those under earthquake excitations, and opposite-sign response factors under wind loads are insensitive to variation of the natural frequency ratio of the two adjacent buildings compared with those under earthquake excitations. The conclusions of this research may be helpful for windresistant and antiseismic design of parallel-placed adjacent high-rise buildings.

\section{Introduction}

With the rapid development of metropolitan cities over the years, high-rise buildings are often constructed in close proximately to each other [1]. Some notable examples of such attractive building systems include the Petronas Twin Towers in Kuala Lumpur, the Marina Bay Sands Hotel, American Coopers in New York, and many more. These slender parallelplaced adjacent high-rise buildings are sensitive to dynamic excitations [2-4]. When these buildings are located in regions prone to hurricanes and earthquakes simultaneously, they may suffer from significant damage in their uncontrolled configurations. Hence, various passive control devices may be installed on these buildings to simultaneously control undesirable excessive dynamic responses induced by wind loads and earthquake excitations [5-7].

In order to design and install passive control devices accurately, characteristics of dynamic responses of parallel-placed adjacent high-rise buildings under wind and earthquake excitations should be investigated to simultaneously control wind- and earthquake-induced vibrations. Unlike earthquake excitations, wind loads acting on the adjacent high-rise buildings may be more complicated [8]. The reason can be mainly attributed to the following two facts: (1) due to the complex interaction of wind and exterior shape of buildings, wind loads include along-wind and across-wind components, which are mainly generated by incoming turbulence and vortex-shedding, respectively [9], and (2) wind loads acting on the target building can be strongly affected by aerodynamic interference if surrounding buildings exist [10-12]. Currently, most of the literature studies are focused on the assessment of structural safety under independent hazards i.e., under earthquakes [13-18] or strong winds [19-22]. However, research interests have been developed amongst engineers and researchers to investigate the design of structures under a combination of extreme multiple hazards [23]. Vulcano [24] 
investigated the dynamic responses of a single building with base-isolated devices subjected to strong wind loads and earthquake excitations to pursue the optimal design of the baseisolation system. Hong and $\mathrm{Gu}$ [25] found that, in the case of tall flexible buildings whose lateral forces are mainly governed by wind loads, the combined loads after considering wind loads and earthquake excitations may be more unfavourable as compared with those involving wind loads in seismic design. Duthinh and Simiu [26] developed a design approach for buildings in regions where strong winds and earthquakes are significant while satisfying the minimum requirements in design standards. Mahmoud and Cheng [27] proposed a probabilistic framework for estimating the lifecycle cost for two steel buildings subjected to different seismic and wind intensities. Zheng et al. [28] presented a multi-hazard-based framework to assess the damage risk of high-rise buildings subjected to wind and earthquake hazards simultaneously. A comparative study of dynamic responses of liquid storage tanks under wind, earthquake, and combined wind and earthquake excitations is presented by Jing et al. [29]. Their results showed that under strong winds the dynamic responses of the liquid storage tank under wind loads alone are larger than those under earthquake excitations, and the dynamic responses under wind-earthquake interaction are larger than those under wind and earthquake excitations alone. Xu et al. [30] proposed an analytical model for an isolated high-rise building with friction pendulum bearing and magnetorheological damper to reduce dynamic responses under combined wind loads and earthquake excitations. Roy and Matsagar [31] investigated the combined wind and earthquake hazards effects on the failure probability of multistorey steel buildings equipped with passive control devices. Most of the aforementioned studies focused on dynamic responses or failure evaluation of a single building under the simultaneous action of wind and earthquake.

To the best of the authors' knowledge, the comparison between the dynamic responses of adjacent high-rise buildings subjected to wind loads and earthquake excitations has not been thoroughly investigated in the literature. Hence, in the present study, an attempt has been made to investigate the dynamic response characteristics of these parallel-placed linked high-rise buildings to control the structural vibrations under strong wind and earthquake excitations. The present study is arranged as follows: firstly, the equations of motion for the adjacent buildings under the two different kinds of dynamic excitations are established. Subsequently, a structure comprising two adjacent high-rise buildings is briefly introduced considering wind loads obtained from wind tunnel tests and natural earthquake records. Finally, an opposite-sign response factor is identified to compare the displacement, velocity, and acceleration responses of the linked adjacent buildings with different natural frequency ratios under wind loads and earthquake excitations.

\section{Mathematical Model of the Adjacent Buildings under Wind and Seismic Excitations}

A lumped-mass sketch of adjacent high-rise buildings is shown in Figure 1. The two buildings, named Building 1 ( $i$ storeys) and

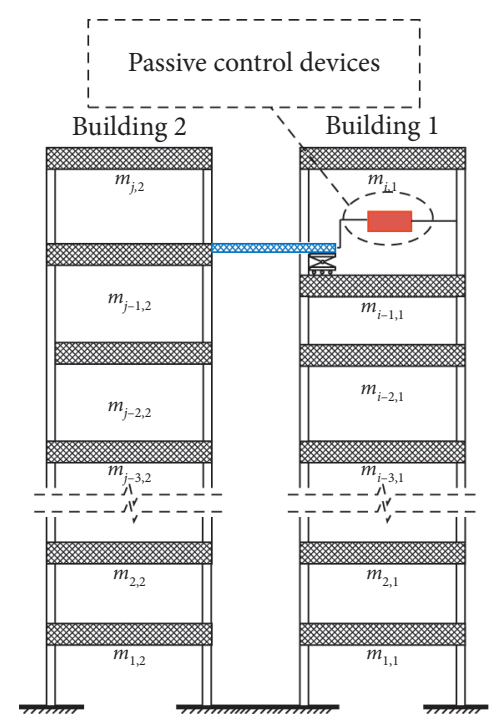

FIgURE 1: The structural sketch of the two adjacent high-rise buildings.

Building 2 ( $j$ storeys), are linked by a corridor with rigid support at one terminal and sliding support at the other terminal. Different passive control devices may be installed at the storey having the same intermediate height as that of the corridor to mitigate the dynamic responses when these responses do not satisfy the requirement of design standards. These different types of passive control devices can be categorized into displacement-dependent such as metal friction dampers [32, 33] or buckling-restrained braces [34], velocitydependent such as fluid viscous dampers [35-39], or acceleration-dependent primarily related to inerter devices [40-42]. Therefore, while selecting suitable passive control devices, the dynamic response characteristics of the adjacent high-rise buildings under wind loads and seismic excitations should be fully considered to obtain a better mitigation efficiency of these devices.

The equations of motion of adjacent high-rise buildings without any passive control devices under wind loads and seismic excitations can be expressed as in equations (1) and (2), respectively.

$$
\begin{aligned}
\mathbf{M} \ddot{\mathbf{X}}(t)+\mathbf{C} \dot{\mathbf{X}}(t)+\mathbf{K X}(t) & =\mathbf{P}(t), \\
\mathbf{M} \ddot{\mathbf{X}}(t)+\mathbf{C} \dot{\mathbf{X}}(t)+\mathbf{K X}(t) & =-\mathbf{M}\{1\} \ddot{x}_{g}(t),
\end{aligned}
$$

where, $\mathbf{M}, \mathbf{C}$, and $\mathbf{K}$ are the mass, damping, and stiffness matrices of the two adjacent high-rise buildings, respectively. The lumped mass and lateral stiffness of each storey can be obtained from the finite element model of the buildings. $\ddot{\mathbf{X}}(t), \dot{\mathbf{X}}(t)$, and $\mathbf{X}(t)$ correspond to the acceleration, velocity, and displacement column vectors of adjacent high-rise buildings, respectively. $\mathbf{P}(t)$ is the wind load vector acting on the center of mass of each storey, which can be obtained from wind tunnel tests of synchronous multipoint pressure measurements. $\ddot{x}_{g}(t)$ is the acceleration of ground motion at time $t$, and $\{1\}$ is a column vector with $(i+j)$ entries, in which all entries are equal to 1 . 
The mass matrix $\mathbf{M}$ can be expressed as

$$
\mathbf{M}=\operatorname{diag}\left[m_{1,1}, m_{2,1} \ldots, m_{i, 1}, m_{1,2}, m_{2,2} \ldots, m_{j, 2}\right],
$$

where $m_{i, 1}$ and $m_{j, 2}$ denote the dead and live loads (properly combined with each other) of the $i^{\text {th }}$ storey of Building 1 and the $j^{\text {th }}$ storey of Building 2 , respectively.

The stiffness matrix $\mathbf{K}$ can be defined as

$$
\mathbf{K}=\left[\begin{array}{cc}
\mathbf{K}_{i \times i, 1} & 0 \\
0 & \mathbf{K}_{j \times j, 2}
\end{array}\right],
$$

where $\mathbf{K}_{i \times i, 1}$ and $\mathbf{K}_{j \times j, 2}$ represent the stiffness matrix of original Building 1 and Building 2, respectively.

The damping matrix $\mathbf{C}$ can be expressed according to the Rayleigh formulation:

$$
\mathbf{C}_{(i+j) \times(i+j)}=a_{0} \mathbf{M}_{(i+j) \times(i+j)}+a_{1} \mathbf{K}_{(i+j) \times(i+j)},
$$

where $a_{0}$ and $a_{1}$ are two scalar coefficients of proportionality.

Since the mass, damping, and stiffness matrices are orthogonal to the mode shape, equations (1) and (2) can be decoupled into the modal coordinates as expressed in equations (6) and (7), respectively.

$$
\begin{aligned}
& \ddot{q}_{k}(t)+2 \xi_{k} \omega_{k} \dot{q}_{k}(t)+\omega_{k}^{2} q_{k}(t)=\frac{P_{k}^{*}(t)}{M_{k}^{*}}, \\
& \ddot{q}_{k}(t)+2 \xi_{k} \omega_{k} \dot{q}_{k}(t)+\omega_{k}^{2} q_{k}(t)=-\left(\frac{-\left\{\phi_{k}\right\}^{T} \mathbf{M}\{1\}}{\left\{\phi_{k}\right\}^{T} \mathbf{M}\left\{\phi_{k}\right\}}\right) \ddot{x}_{g},
\end{aligned}
$$

where $q_{k}(t), \xi_{k}, \omega_{k}, P_{k}^{*}(t), M_{k}^{*}$, and $\phi_{k}$ denote the $k^{\text {th }}$ order generalized coordinates, damping ratio, natural circular frequency, generalized aerodynamic force, and generalized mass, vibration mode, respectively. The superscript $T$ denotes the transpose operator, and the modal participation coefficient $\gamma_{k}$ is defined as

$$
\gamma_{k}=\frac{\left\{\phi_{k}\right\}^{T} \mathbf{M}\{1\}}{\left\{\phi_{k}\right\}^{T} \mathbf{M}\left\{\phi_{k}\right\}} .
$$

The time-domain integration method, i.e., Duhamel's integral, is used to solve the generalized coordinate $q_{k}(t)$ under wind and earthquake excitations, which are formulated as in equations (9) and (10), respectively.

$$
\begin{aligned}
& q_{k}(t)=\frac{1}{M_{k}^{*} \omega_{d k}} \int_{0}^{t} P_{k}^{*}(\tau) e^{-\xi_{k} \omega_{k}(t-\tau)} \sin \omega_{d k}(t-\tau) \mathrm{d} \tau, \\
& q_{k}(t)=-\left(\frac{1}{\omega_{d k}}\right) \int_{0}^{t} \gamma_{k} \ddot{x}_{g}(\tau) e^{-\xi_{k} \omega_{k}(t-\tau)} \sin \omega_{d k}(t-\tau) \mathrm{d} \tau,
\end{aligned}
$$

where $\omega_{d k}$ is the $k^{\text {th }}$ damped natural frequency of the structure.

According to the modal superposition method, the displacement response of the structure at arbitrary $t$ can be expressed as

$$
\{x(t)\}=\sum_{k=1}^{N}\left\{\phi_{k}\right\} q_{k}(t)
$$

where $N$ is the number of the mode shape involved while calculating the displacement time history of the structure.

\section{Case Study}

The following section introduces a case study of two adjacent high-rise buildings and the related excitations to evaluate the dynamic responses: in particular, wind loads are obtained from wind tunnel tests of synchronous multipoint pressure measurements, while 44 natural ground-motion records are considered for earthquake-induced excitations.

3.1. A Brief Introduction of the Two Adjacent High-Rise Buildings. The same structure previously considered by De Domenico et al. [43] is analyzed as a case, comprising two adjacent high-rise buildings whose main properties are summarized as follows. Building 1 has 59 storeys with 268 meters height and Building 2 consists of 55 storeys with a height of 210.2 meters. The main dimensions of the adjacent buildings and the definition of the coordinate system for structural analysis and wind directions are shown in Figures 2(a) and 2(b).

The distribution of lumped masses of the two buildings is presented in Figure 3(a)The lateral stiffness along the $x$-axis of two buildings is smaller than that along the $y$-axis; as a result, the most unfavourable dynamic response will probably occur along the $x$-axis. Hence, only lateral stiffness along the $x$-axis is plotted in Figure 3(b).

According to the mass and stiffness matrices of the individual adjacent buildings, the fundamental frequencies of Building 1 and Building 2 are obtained. The first five natural frequencies of the individual buildings are listed in Table 1. As shown in Table 1, the natural frequency ratio (NFR) which is defined as the ratio of the first natural frequency of Building 1 to that of Building 2 can be estimated as $0.86 / 1$. To investigate the effects of natural frequency ratio on dynamic responses of adjacent buildings under different excitations, the mass of Building 2 is adjusted so as to make its first natural frequency equal to that of Building 1 , which means that the natural frequency ratio is equal to $1 / 1$.

3.2. Wind Tunnel Test and Ground-Motion Time Histories. Wind tunnel tests of synchronous multipoint pressure measurement are carried out in the wind tunnel laboratory of Shantou University. The scale ratio of the test model to the prototype of the buildings is $1: 300$. In the wind tunnel tests, the B-type wind field is simulated according to the Chinese building code [45]. The wind tunnel tests are conducted for 24 wind directions ranging from $0^{\circ}$ to $345^{\circ}$ at an interval of $15^{\circ}$ to investigate the effect of wind direction on the dynamic responses of the structure. For the displacement and acceleration responses of the buildings, the basic wind pressures are assumed to be $0.6 \mathrm{kPa}$ and $0.35 \mathrm{kPa}$ (corresponding to 50-year and 10-year return periods, respectively). More 

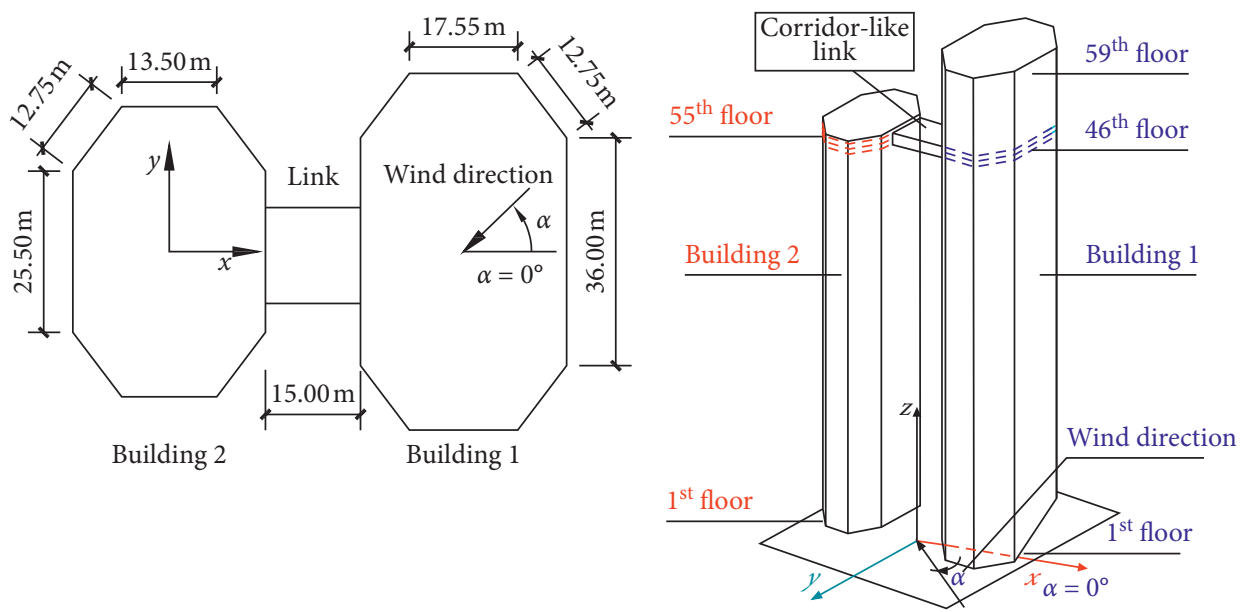

(a)

(b)

Figure 2: (a) Plane view of adjacent buildings and definition of the coordinate system and wind direction [8] and (b) axonometric sketch of two buildings [43].

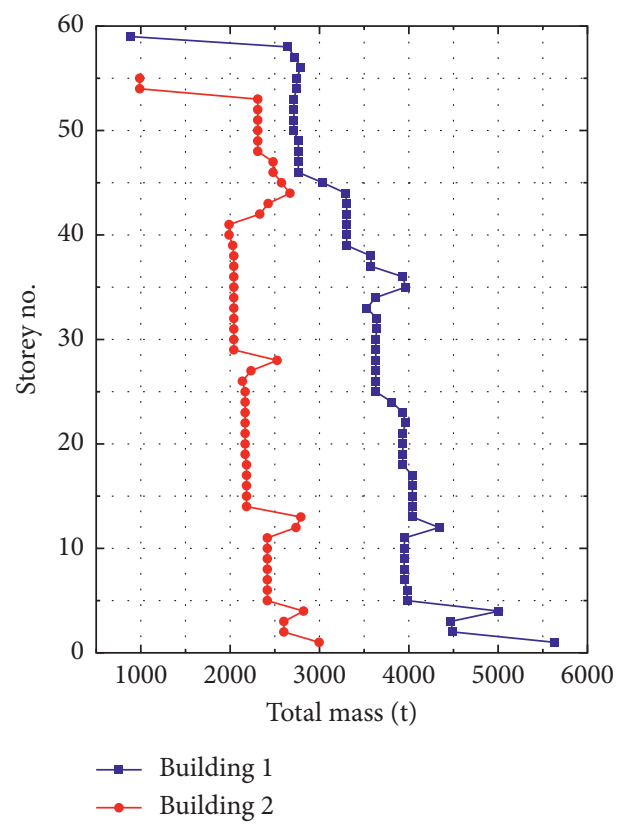

(a)

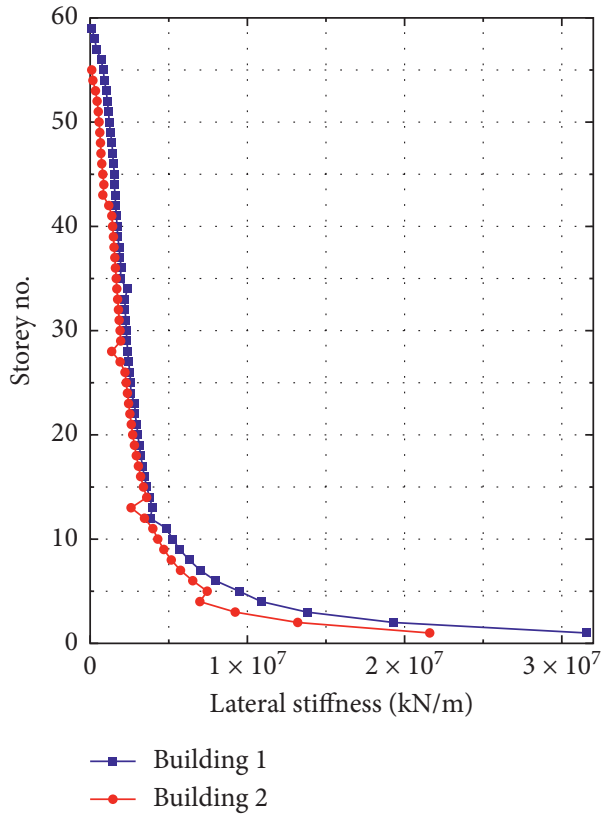

(b)

FIgURE 3: Distribution of (a) lumped masses and (b) lateral stiffness of the two buildings along the $x$-axis [44].

TABLE 1: Natural frequencies of individual buildings.

\begin{tabular}{lccccc}
\hline Frequency $(\mathrm{Hz})$ & $f_{1}$ & $f_{2}$ & $f_{3}$ & $f_{4}$ & $f_{5}$ \\
\hline Building 1 & 0.139 & 0.347 & 0.554 & 0.756 & 0.959 \\
Building 2 & 0.161 & 0.399 & 0.636 & 0.866 & 1.090 \\
\hline
\end{tabular}

detailed information about the wind tunnel test can be found in the literature [44].

Based on the results obtained from wind tunnel tests, the normalized power spectral density (PSD) of base shear forces on Building 1 and Building 2 at across-wind direction is plotted in Figure 4. The PSD curves of Building 1 and Building 2 have obvious peaks corresponding to the dimensionless values $f B / U_{H}=0.107$ and 0.120 , where $f$ represents frequency measuring by $\mathrm{Hz}, B$ is width of the individual building, $U_{H}$ denotes mean wind speed at top of the buildings corresponding to 50-year return period, and $S(f)$ and $\sigma_{z}$ represent self-power spectrum and root mean square of the base shear forces, respectively.

With regard to the earthquake excitation, the dynamic responses of adjacent high-rise buildings are evaluated under 44 natural ground-motion records, which are two horizontal components of 22 earthquakes obtained from the FEMA P-695 far-field record set [46]. Some seismological information of the 22 earthquakes is listed in Table 2. These ground-motion records have been used in previous 


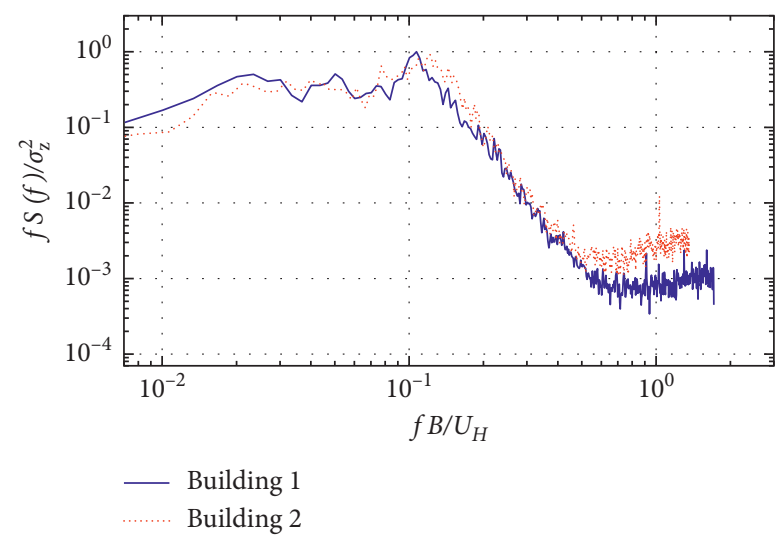

FIGURE 4: Normalized PSD of base shear forces at the across-wind direction.

TABLE 2: Information of 22 considered earthquakes from FEMA P-695 far-field record set [46].

\begin{tabular}{|c|c|c|c|c|c|}
\hline \multirow{2}{*}{ ID no. } & \multicolumn{3}{|c|}{ Earthquake } & \multicolumn{2}{|c|}{ Recording station } \\
\hline & Magnitude & Year & Name & Name & Owner \\
\hline 1 & 6.7 & 1994 & Northridge & Beverly Hills-Mulhol & USC \\
\hline 2 & 6.7 & 1994 & Northridge & Canyon Country-WLC & USC \\
\hline 3 & 7.1 & 1999 & Duzce, Turkey & Bolu & ERD \\
\hline 4 & 7.1 & 1999 & Hector Mine & Hector & SCSN \\
\hline 5 & 6.5 & 1979 & Imperial Valley & Delta & UNAMUCSD \\
\hline 6 & 6.5 & 1979 & Imperial Valley & El Centro Array \#11 & USGS \\
\hline 7 & 6.9 & 1995 & Kobe, Japan & Kobe, Japan & CUE \\
\hline 8 & 6.9 & 1995 & Kobe, Japan & Shin-Osaka & CUE \\
\hline 9 & 7.5 & 1999 & Kocaeli, Turkey & Duzce & ERD \\
\hline 10 & 7.5 & 1999 & Kocaeli, Turkey & Arcelik & KOERI \\
\hline 11 & 7.3 & 1992 & Landers & Yermo Fire Station & CDMG \\
\hline 12 & 7.3 & 1992 & Landers & Coolwater & SCE \\
\hline 13 & 6.9 & 1989 & Loma Prieta & Capitola & CDME \\
\hline 14 & 6.9 & 1989 & Loma Prieta & Gilroy Array \#3 & CDMG \\
\hline 15 & 7.4 & 1990 & Manjil, Iran & Abbar & BHRC \\
\hline 16 & 6.5 & 1987 & Superstition Hills & El Centro Imp. Co. & CDMG \\
\hline 17 & 6.5 & 1987 & Superstition Hills & Poe Road (Temp) & USGS \\
\hline 18 & 7.0 & 1992 & Cape Mendocino & Rio Dell Overpass & CDMG \\
\hline 19 & 7.6 & 1999 & Chi-Chi, Taiwan & CHY101 & CWB \\
\hline 20 & 7.6 & 1999 & Chi-Chi, Taiwan & TCU045 & CWB \\
\hline 21 & 6.6 & 1971 & San Fernando & LA-Hollywood Stor & CDMG \\
\hline 22 & 6.5 & 1976 & Friuli, Italy & Tolmezzo & -- \\
\hline
\end{tabular}

researches to investigate the mitigation effects of different passive control devices $[47,48]$. The individual and average PSDs of 44 recorded earthquakes are shown in Figure 5. It is observed that the predominant frequencies of these earthquake excitations concentrate on a higher frequency range as compared to those of wind loads as shown in Figure 4.

\section{Dynamic Response Analysis of Adjacent Buildings under Wind and Earthquake Excitations}

According to the mathematical model described in Section 2, wind loads and earthquake excitations in Section 3, the time history of displacement, velocity, and acceleration response for the adjacent high-rise buildings under wind loads and seismic excitations are estimated numerically. To quantitatively compare these response characteristics, an opposite- sign response factor $F_{o p p}$ is introduced in this study, which is defined as

$$
F_{\text {opp }}=\frac{T_{\text {opp }}}{T_{\text {total }}} \times 100 \%,
$$

where $T_{\text {opp }}$ is the sum of the time intervals during which fluctuating components of wind-induced displacement responses or, similarly, total velocity and acceleration responses of buildings (the mean values of velocity and acceleration responses are equal to zero) have opposite sign, and $T_{\text {total }}$ is the total statistical time of dynamic responses.

4.1. Comparison of Displacement Responses. According to equation (1) to equation (11), the time histories of dynamic displacement responses of adjacent high-rise buildings under wind loads and earthquake excitations are evaluated. 


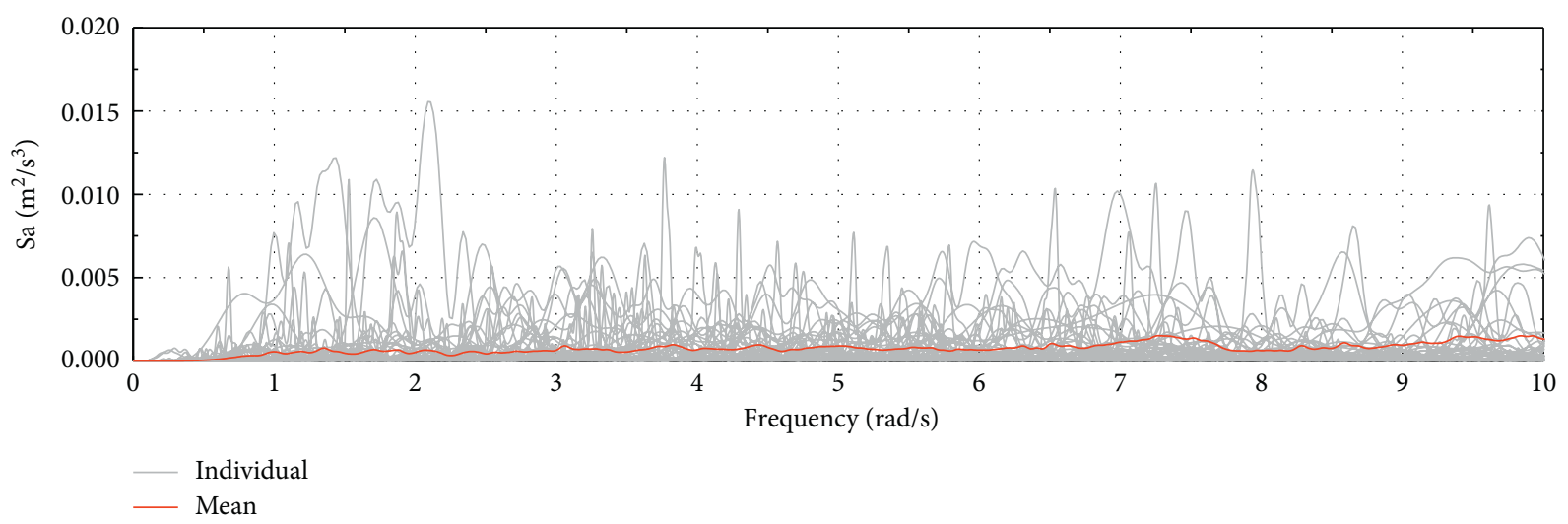

FIgure 5: The individual and mean PSDs of the 44 recorded earthquakes belonging to the FEMA P695 far-field record set [40].

The total wind-induced responses of structures can be decomposed into mean value and fluctuating components. Previous literature $[8,43,44,49,50]$ showed that the passive control devices can only suppress the fluctuating vibration, thus while investigating dynamic response characteristics, only the fluctuating response is analyzed. For the clarity of the figures, Figure 6 shows only the 50-second segment of fluctuating displacement time history of the adjacent highrise buildings and the shaded part indicates that the direction of displacement of the two buildings is opposite; i.e., if the sign of one response is negative, the other sign is positive. Figures $6(\mathrm{a})-6(\mathrm{c})$ illustrate the time history of the wind-induced fluctuating displacement responses at the height of 210.2 meters of the adjacent buildings with a natural frequency ratio of $0.86 / 1$ at $0^{\circ}, 90^{\circ}$, and $180^{\circ}$ wind directions, respectively. Figure 6(d) presents the time history of displacement for the adjacent buildings at the height of 210.2 meters under the No. 10 earthquake excitation.

Once the time histories of wind-induced and earthquake-induced displacement responses are obtained, the opposite-sign displacement factor of the adjacent buildings at the height of 210.2 meters may be estimated according to equation (12). The total statistical time for seismic responses is the same as recorded time of each ground motion, while that of wind-induced responses is set to be 600 seconds. The variations of opposite-sign displacement factor with wind directions and different seismic excitations are shown in Figure 7 . The red dashed line in the figure represents the mean value of factors of wind directions and earthquake excitations, respectively. Figure $7(a)$ indicates that windinduced opposite-sign displacement factor hardly varies with wind directions, while it is nearly not affected by the natural frequency ratio. Figure $7(\mathrm{~b})$ indicates that the opposite-sign factor of the two buildings with the natural frequency ratio of $0.86 / 1$ is much larger than that with the natural frequency ratio of $1 / 1$ under the majority of seismic excitations. The mean value (for all the 44 seismic records) of the opposite-sign displacement response factor is $36.5 \%$ when the natural frequency ratio is $0.86 / 1$, and it is reduced to $11.1 \%$ when the natural frequency ratio is $1 / 1$.

Figure 8 shows the variation of opposite-sign displacement factor with the height of buildings under wind and seismic excitations. Figure 8(a) indicates that the factors under the four wind directions do not vary significantly with the height of the buildings and are insensitive to the natural frequency ratio. Figure 8(b) illustrates that the mean value of the opposite-sign factor of the two buildings subjected to seismic excitations is much smaller when the natural frequency ratio is equal to $1 / 1$ than that when the natural frequency ratio is equal to $0.86 / 1$ at any height of the two buildings.

4.2. Comparison of Velocity Responses. The velocity response time histories can be obtained from the derivative of the displacement time histories with respect to time. Figures 9(a) and 9(b) show the time histories of velocity response at a height of 210.2 meters of the two buildings with the natural frequency ratio being 0.86/1 under across-wind direction $\left(90^{\circ}\right)$ and the No. 10 seismic excitation, respectively. The shaded part in Figure 9means that the velocity responses of the two buildings have the opposite sign.

The variations of the opposite-sign velocity factor with different wind directions and earthquake excitations are shown in Figure 10. Figure 10(a) indicates that the windinduced velocity factors are insensitive to wind directions and natural frequency ratios of the two buildings since all the values of factors approach around 50\% under 24 wind directions and different natural frequency ratios. Figure 10(b) illustrates that factors related to velocity responses under seismic excitations are sensitive to natural frequency ratio of the two buildings. Under most of the seismic excitations, the factors are relatively lower when the natural frequency ratio is $1 / 1$ than that at the condition of the natural frequency ratio being $0.86 / 1$. The mean values of the opposite-sign factors for seismic excitation are $40.3 \%$ and $25.0 \%$ corresponding to natural frequency ratios of $0.86 / 1$ and $1 / 1$, respectively.

Figure 11 presents the variation of the opposite-sign velocity factor with the varying height of the two buildings under wind loads and earthquake excitations, respectively. Figure 11(a) illustrates that the factors remain steady with the varying height and natural frequency ratio of the two adjacent buildings, and these values of factors lie around $50 \%$ at the four typical wind directions. Figure 11(b) indicates that the mean value of the velocity 


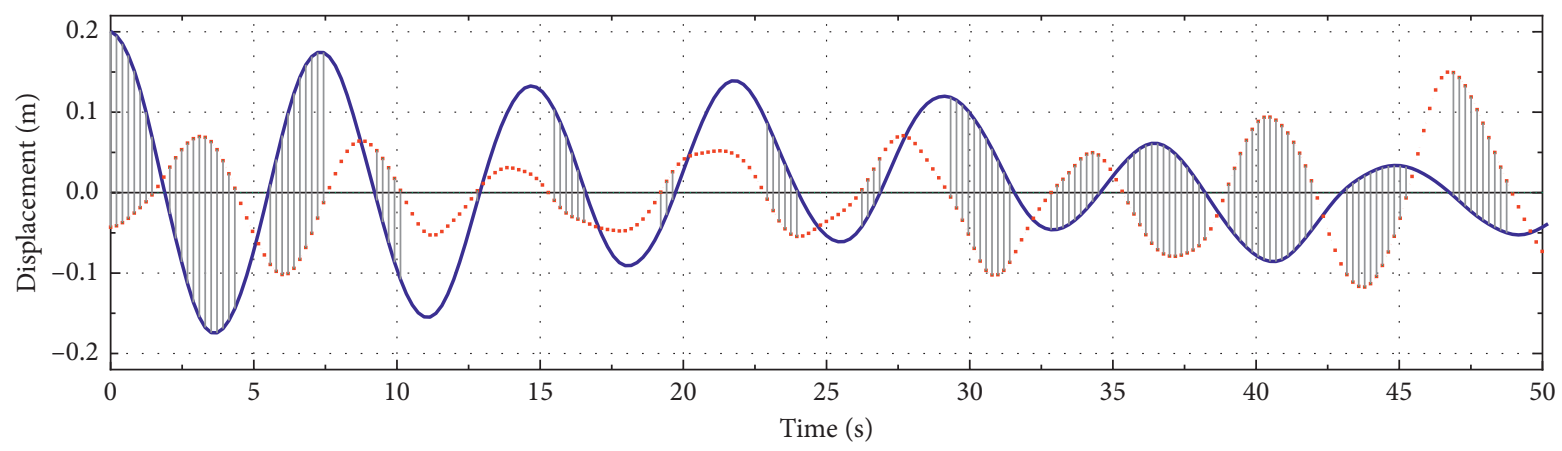

— Building 1

..... Building 2

(a)

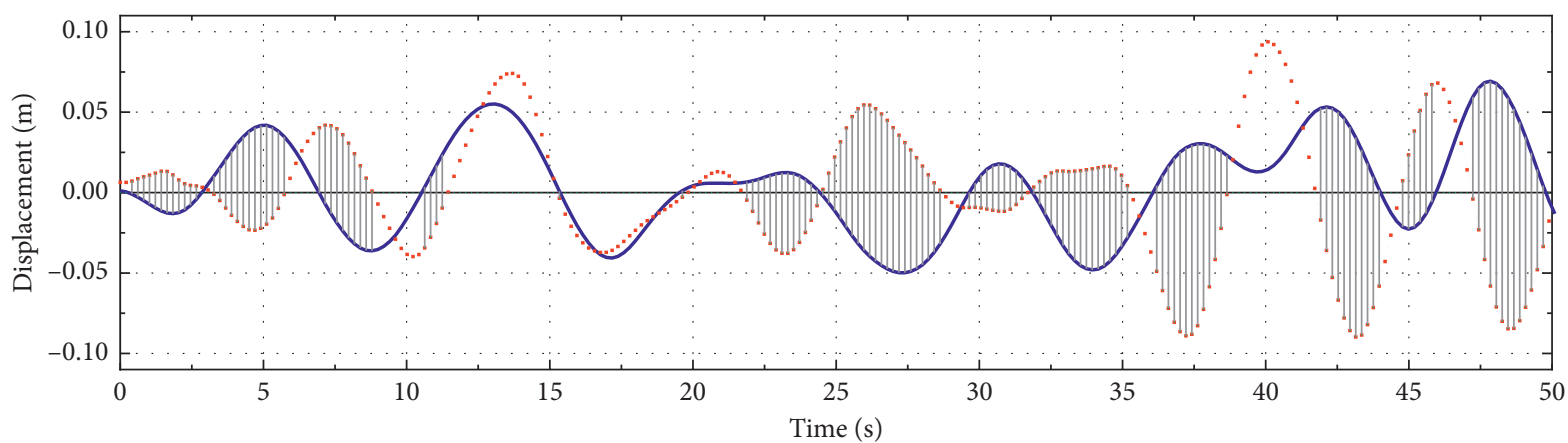

_ Building 1

… Building 2

(b)

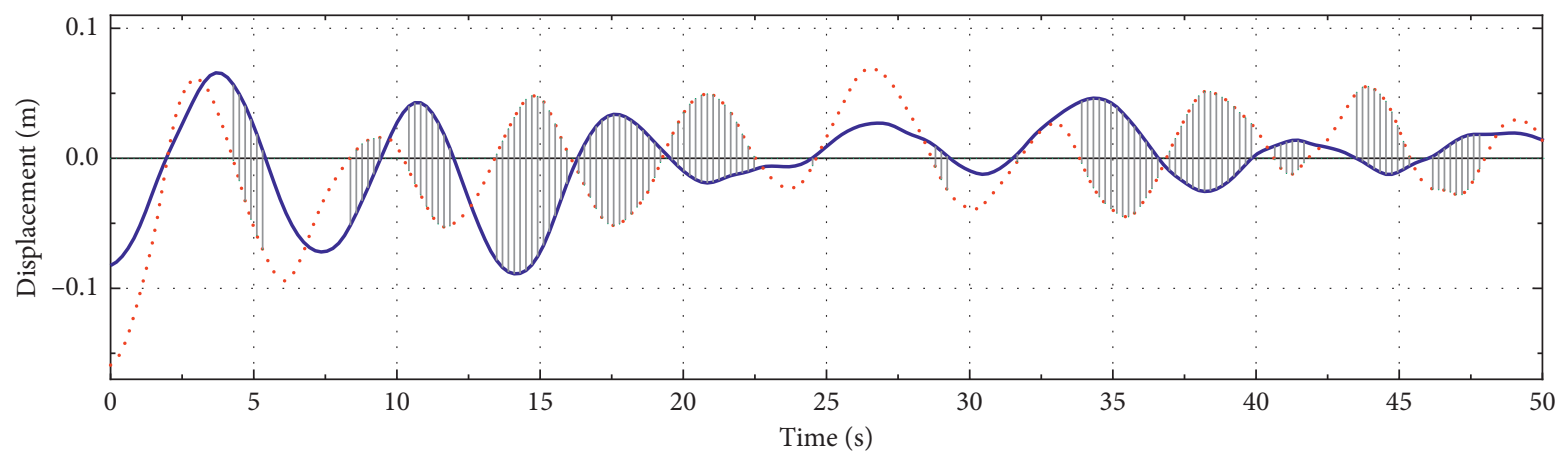

— Building 1

..... Building 2

(c)

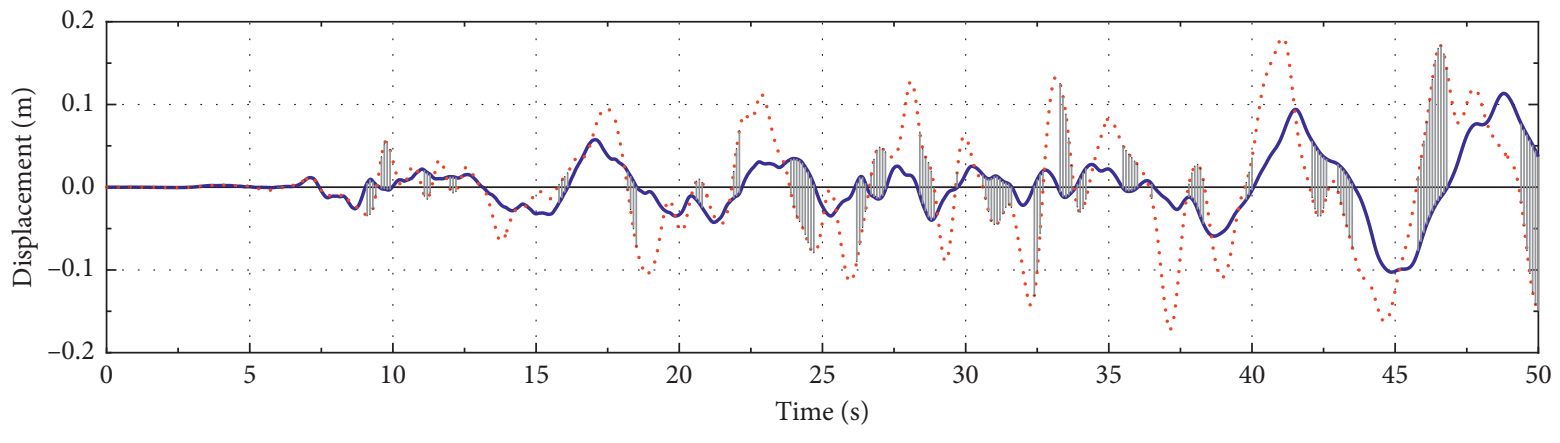

Building 1

Building 2

(d)

Figure 6: Time histories of displacement responses at $210.2 \mathrm{~m}$ height under (a) $0^{\circ}$ wind direction, (b) $90^{\circ}$ wind direction, (c) $180^{\circ}$ wind direction, and (d) the No. 10 earthquake excitation. 


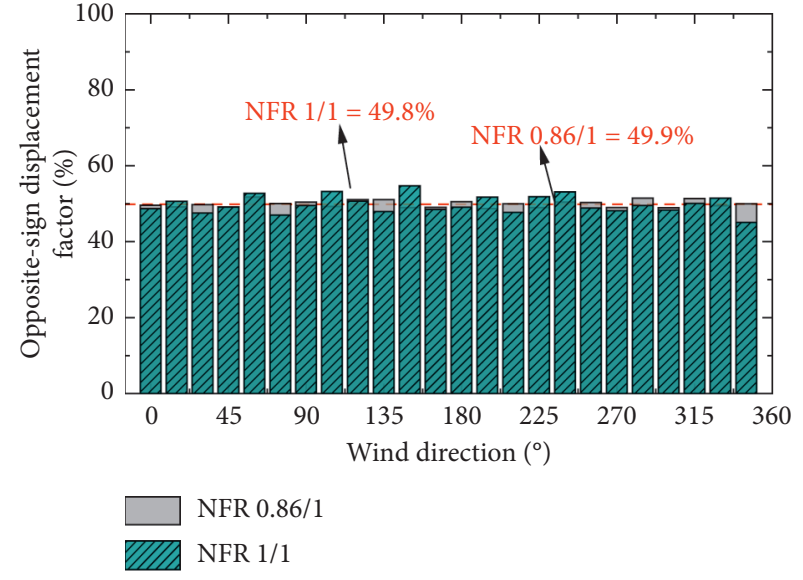

(a)

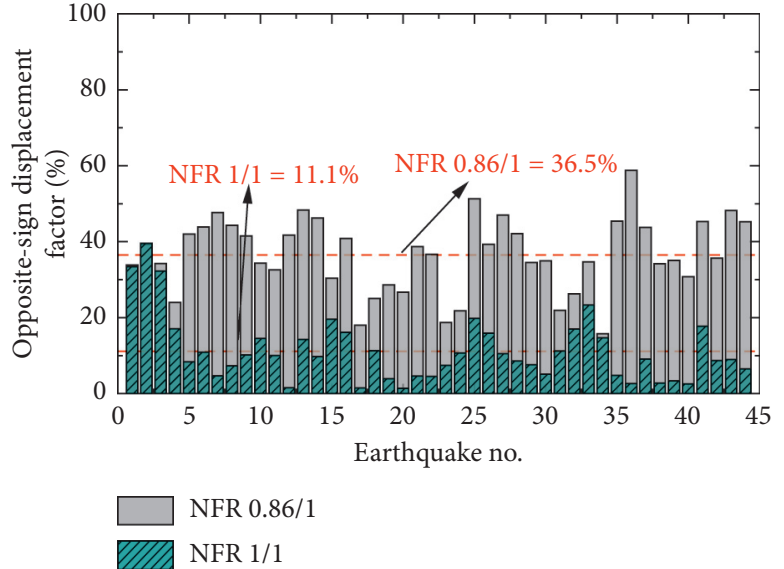

(b)

FIGURE 7: Variation of opposite-sign displacement factor at $210.2 \mathrm{~m}$ height under (a) 24 wind directions and (b) 44 earthquake excitations.

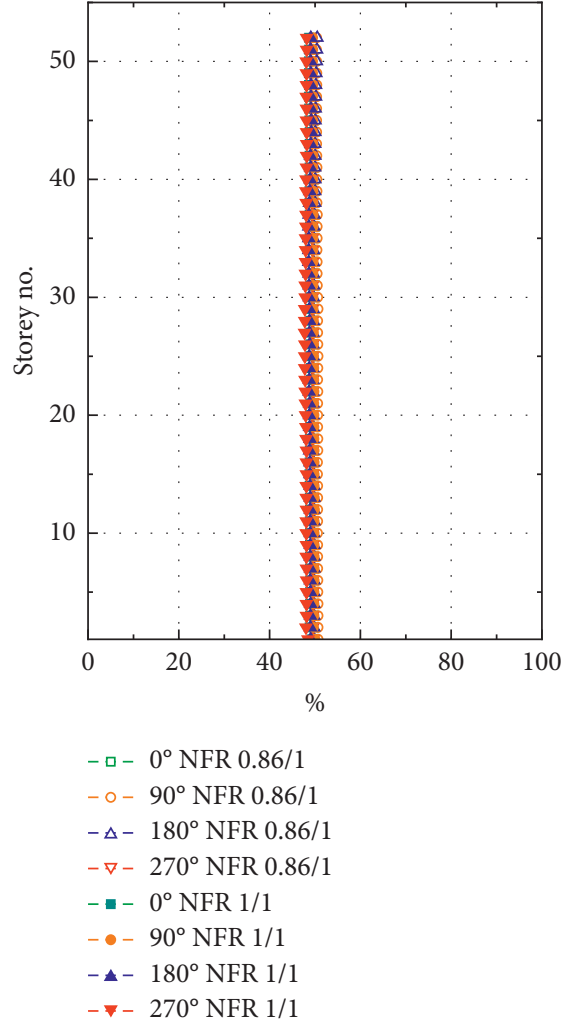

(a)

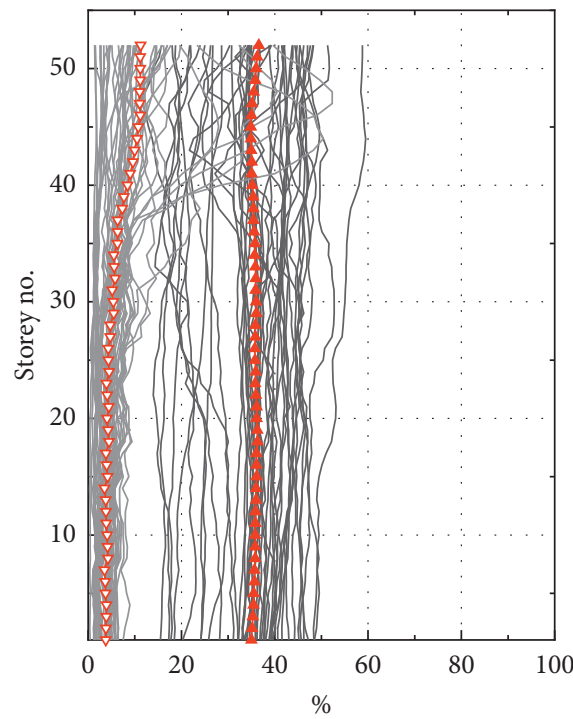

NFR $0.86 / 1$, individual

$\triangle$ NFR $0.86 / 1$, mean

— NFR $1 / 1$, individual

$\rightarrow$ NFR $1 / 1$, mean

FiguRE 8: Variation of opposite-sign displacement factor with height of buildings under (a) wind loads and (b) 44 earthquake excitations.

factor of the two buildings in the case of natural frequency being $0.86 / 1$ is larger than that when natural frequency ratio is $1 / 1$ at any height of the two buildings under seismic excitations.
4.3. Comparison of Acceleration Responses. The acceleration response time histories of the adjacent buildings under wind loads and seismic excitations are estimated in this section. Figures 12 (a) and 12(b) show a 50-second time history of 


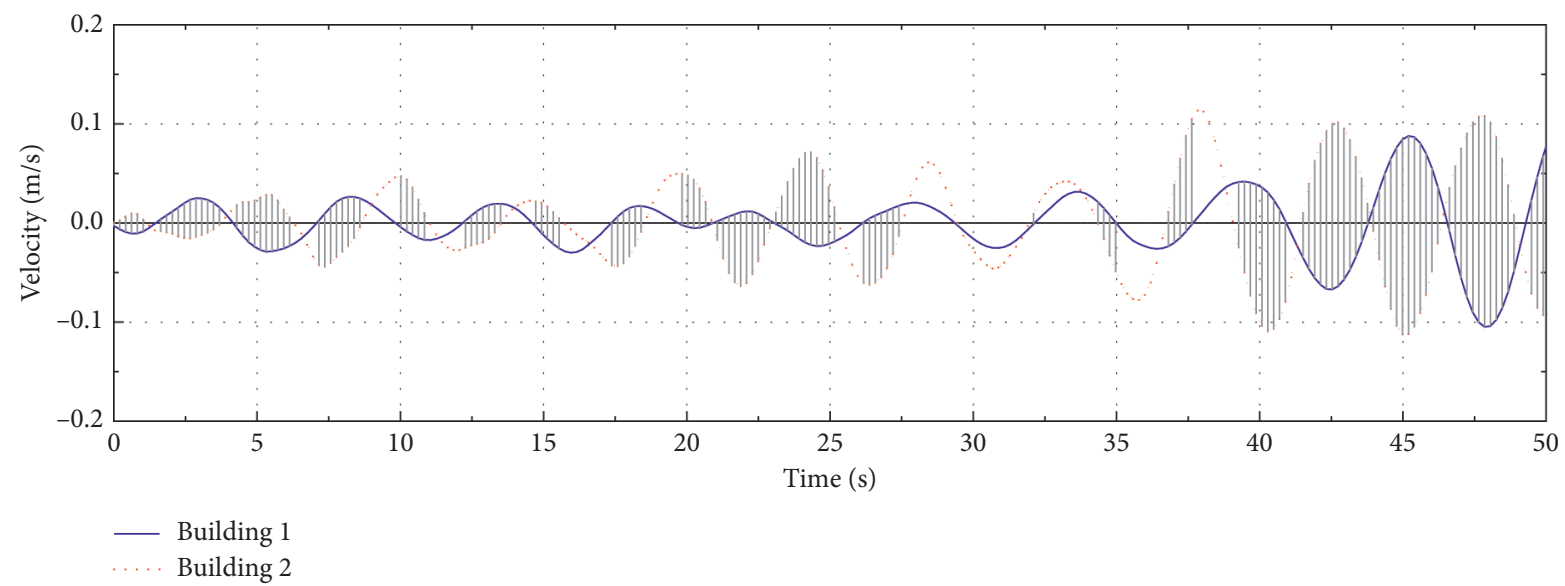

(a)

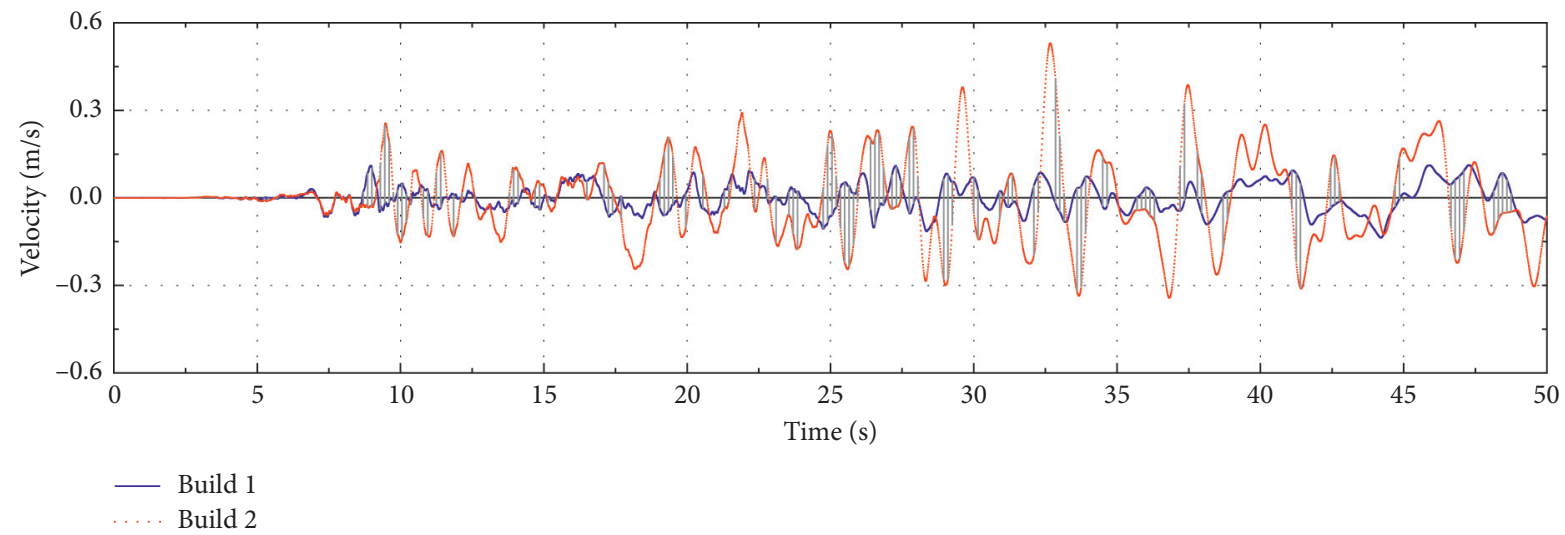

(b)

Figure 9: Time histories of velocity responses at $210.2 \mathrm{~m}$ height under (a) $90^{\circ}$ wind direction and (b) the No. 10 earthquake excitation.

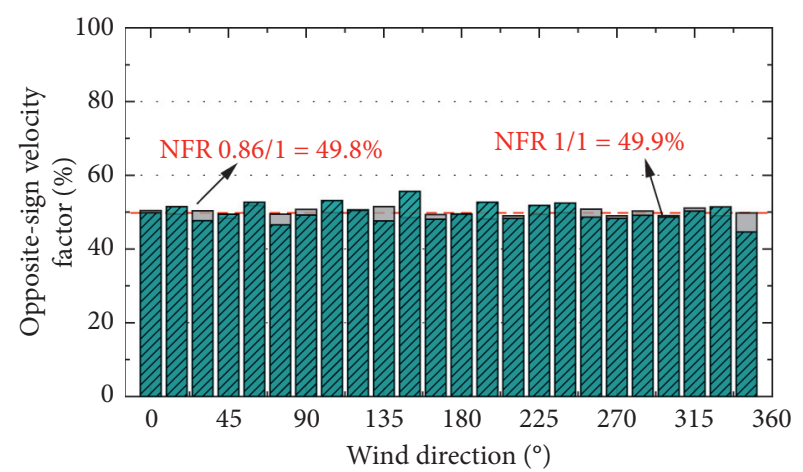

NFR 0.86/1

NFR $1 / 1$

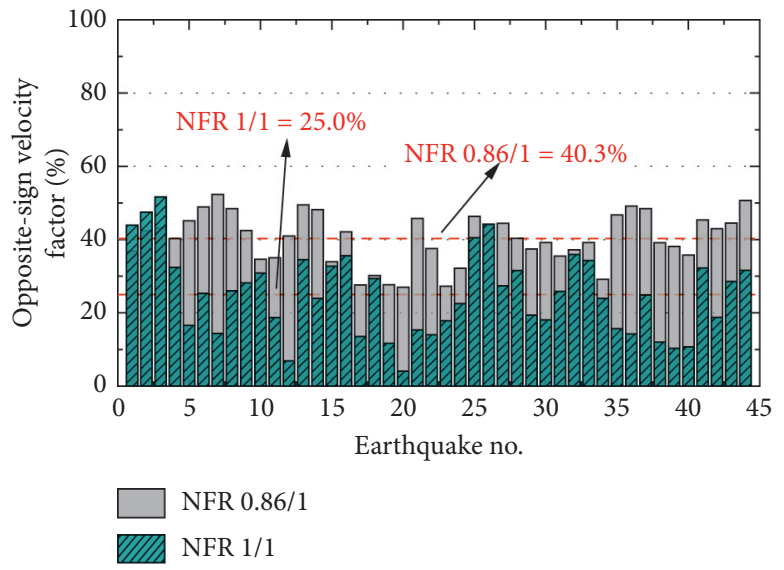

(b)

FIgURE 10: Variation of opposite-sign velocity factor at $210.2 \mathrm{~m}$ height under (a) 24 wind directions and (b) 44 earthquake excitations.

acceleration responses of the two buildings under the acrosswind direction $\left(90^{\circ}\right)$ and the No. 10 earthquake excitation respectively.
Figure 13 shows the variation of the opposite-sign acceleration response factor with different wind directions and earthquake excitations. Figure 13(a) indicates that the wind- 


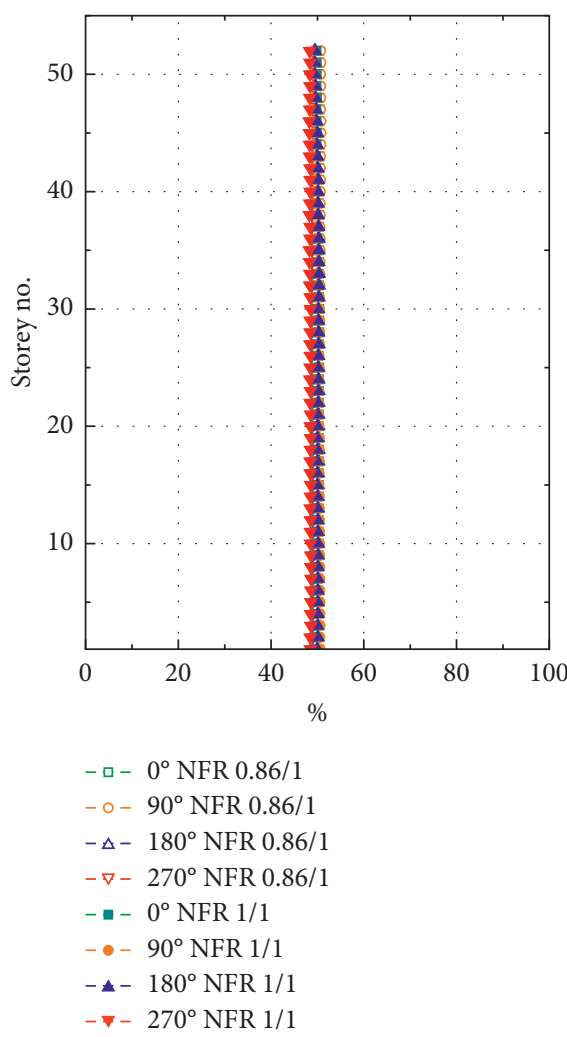

(a)

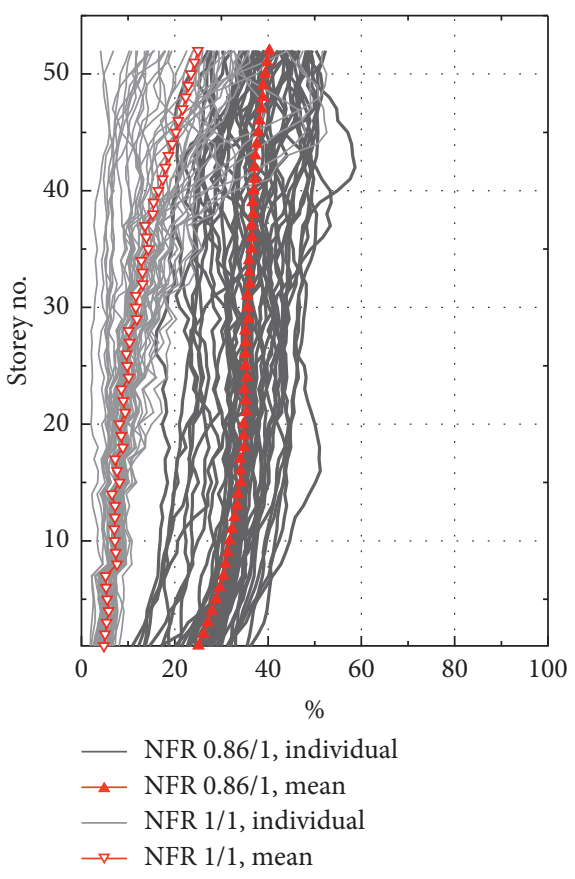

(b)

FIGURE 11: Variation of opposite-sign velocity factor with height of buildings under (a) wind loads and (b) 44 earthquake excitations.

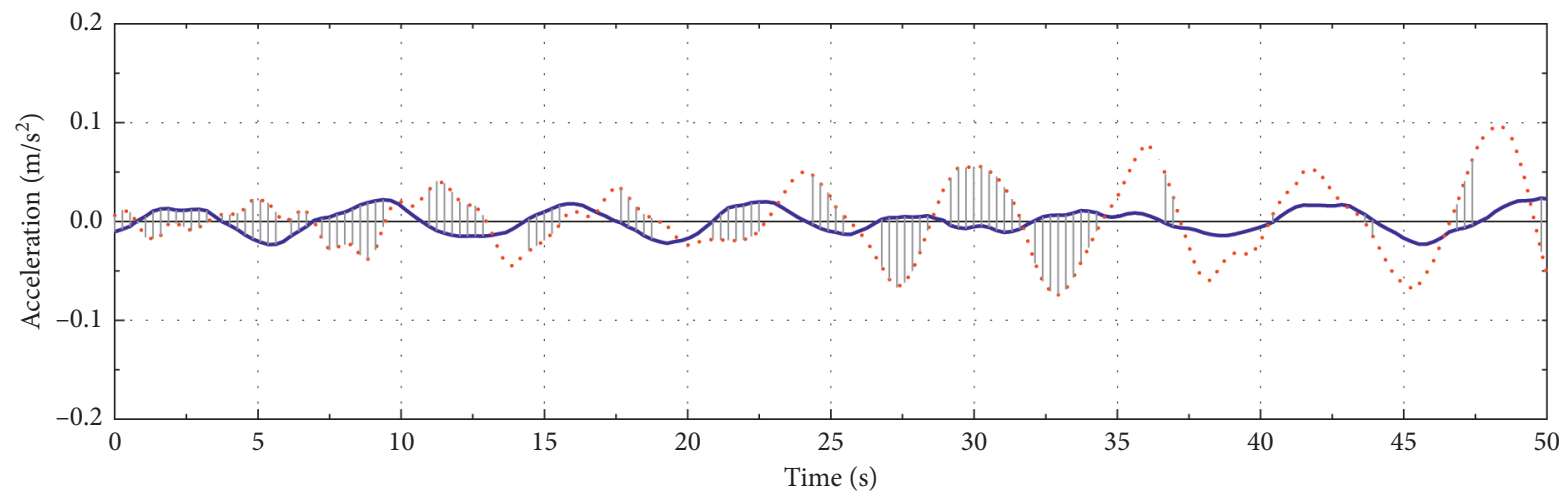

- Building 1

...... Building 2

(a)

Figure 12: Continued. 


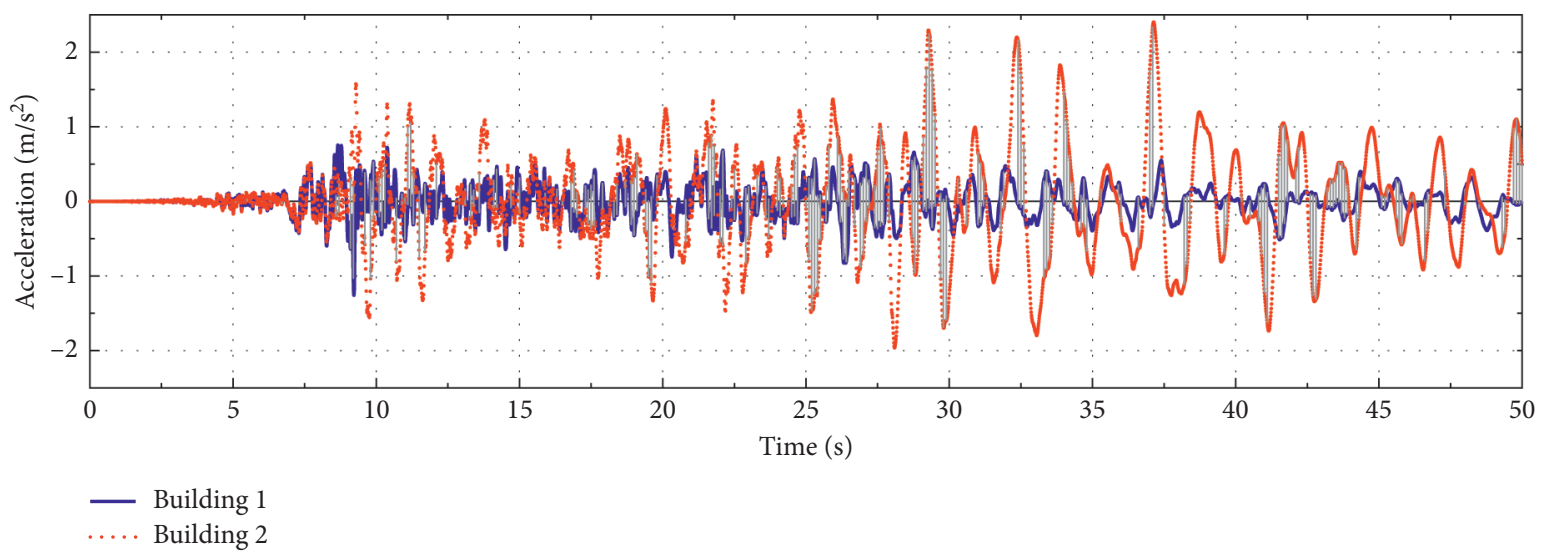

(b)

Figure 12: Time histories of acceleration responses at $210.2 \mathrm{~m}$ height under (a) $90^{\circ}$ wind direction and (b) the No. 10 earthquake excitation.

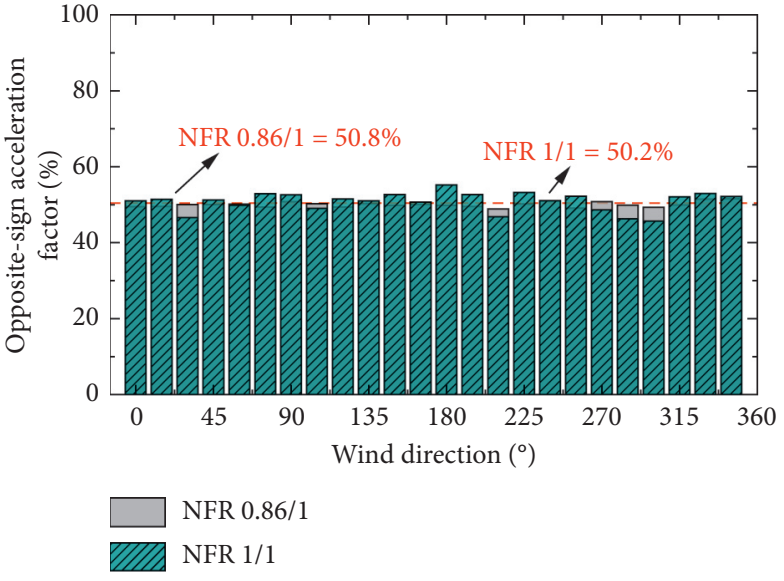

(a)

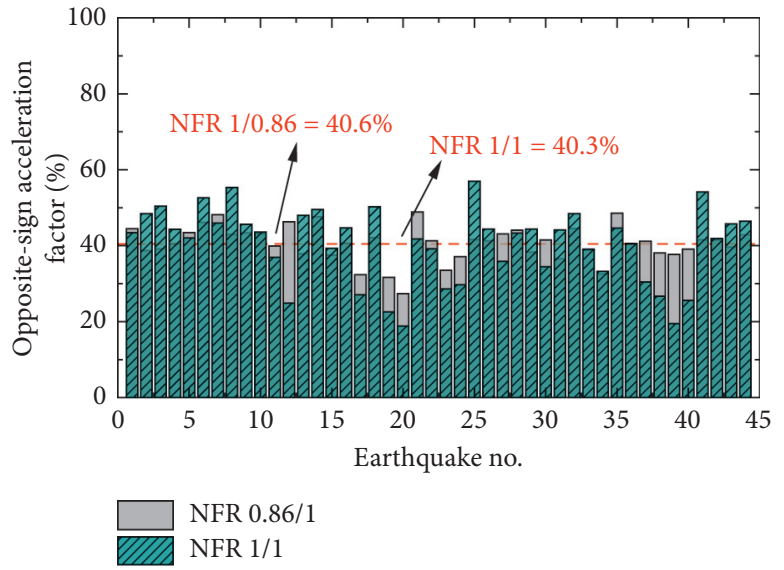

(b)

FIGURE 13: Variation of opposite-sign acceleration factor at $210.2 \mathrm{~m}$ height under (a) 24 wind directions and (b) 44 earthquake excitations.

induced acceleration response factor remains almost invariant while changing wind directions and natural frequency ratio of adjacent buildings, and the mean value for all wind directions in each working condition still lies around $50 \%$. As for earthquake excitations, Figure 13(b) demonstrates that the variation of the earthquake-induced acceleration response factors caused by the changes in natural frequency ratio is not as significant as that of the displacement or velocity response factor shown in Figures 7(b) and $10(\mathrm{~b})$, respectively. The mean value of the opposite-sign acceleration response factor under the 44 earthquake excitations is $40.6 \%$ when the natural frequency ratio is $0.86 / 1$, while the factor is $40.3 \%$ when natural frequency ratio equals to $1 / 1$.

Figure 14 presents the variation of opposite-sign acceleration response factor with the height of two buildings under wind and seismic excitations. Figure 14(a) shows that the acceleration response factors are almost unaffected with the changing height of the building and natural frequency ratios of the two buildings at the four wind directions, which is similar to the variation of wind-induced velocity response factor with height as shown in Figure 11(a). With regard to the seismic excitation, Figure 14(b) indicates that the acceleration response factors at the top storeys of the adjacent buildings with natural frequency ratio of $1 / 1$ are equal to the case when natural frequency ratio is $0.86 / 1$.

\section{Conclusion and Discussion}

In the present work, an opposite-sign response factor is proposed to compare the characteristics of the dynamic responses of two adjacent high-rise buildings under wind loads and earthquake excitations, respectively. This factor is defined as the ratio between the time duration during which 


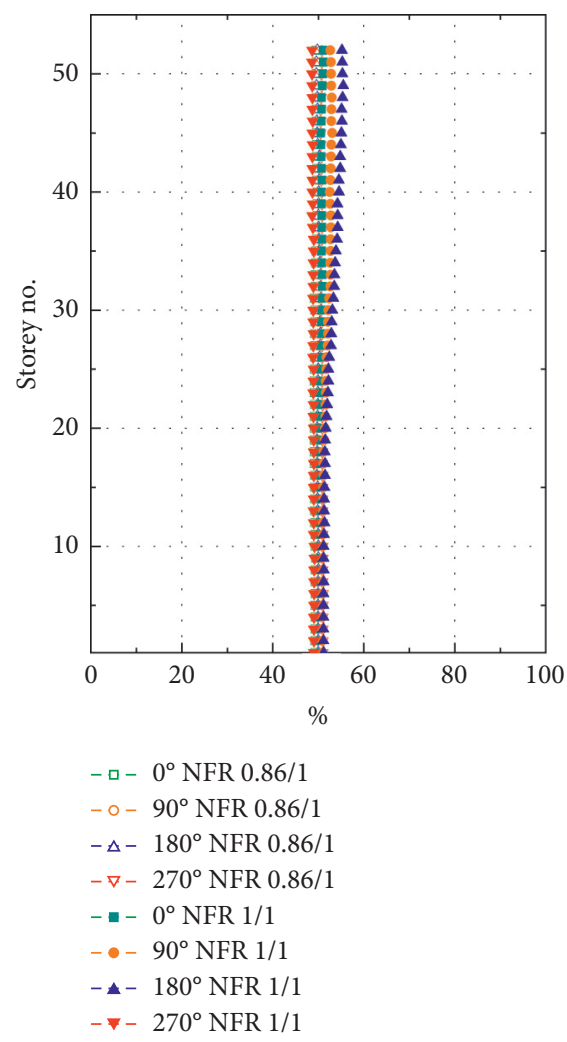

(a)

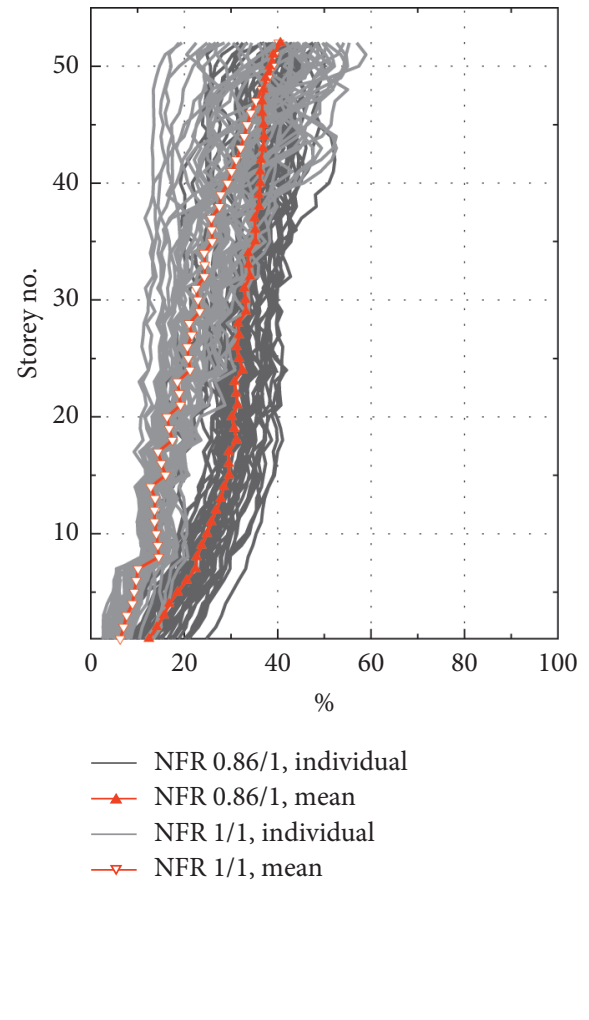

(b)

FIGURE 14: Variation of opposite-sign acceleration factor with height of buildings under (a) wind loads and (b) 44 earthquake excitations.

dynamic responses of the adjacent buildings have the opposite sign and the total statistical time of dynamic responses. The following conclusions are obtained as a result of the present research.

(1) For fluctuating displacement responses, the opposite-sign displacement response factors vary more significantly with different earthquake excitations than that under different wind directions. Besides, these factors of seismic excitations are more sensitive to changes in the natural frequency ratio of the two buildings as compared to wind loads.

(2) In terms of the velocity responses, the opposite-sign velocity response factors remain almost constant with change in both wind directions and the natural frequency ratio of the two buildings, under wind loads. However, under earthquake excitations, these factors vary with different earthquake records and natural frequency ratios. Furthermore, the mean value of the wind-induced factor is larger than that obtained under 44 seismic factors.

(3) Regarding acceleration responses, results of windinduced opposite-sign acceleration factors are similar to those of wind-induced velocity responses, and the mean values of wind-induced acceleration factors are also larger than those of 44 seismic excitations. Nevertheless, the seismic acceleration factors do not vary significantly with different earthquake records and natural frequency ratios as compared to that of seismic displacement and velocity responses.

In general, the opposite-sign dynamic response factors of the adjacent buildings under the action of wind loads are larger than those under earthquake excitations. This result implies that when inter-building passive control devices are installed to mitigate dynamic responses of the two adjacent high-rise buildings, the mitigation efficiency of the devices for wind-induced vibration control is better than the seismic vibration control. This anticipation is consistent with the previous works $[8,43,44,48]$ from the authors dealing with wind-induced and earthquake-induced vibration mitigation with inter-building passive control devices. In these researches, different acceleration-dependent tuned inerter dampers, i.e., TMDI and TLCDI, were employed to control wind-induced and seismic responses of the two adjacent high-rise buildings analyzed in the present work. After the installation of TMDI on the two adjacent buildings, the mean reduction coefficients of the top-level acceleration are $37.5 \%$ for Building 1 and $45.2 \%$ for Building 2 at the acrosswind direction, while the maximum corresponding reduction coefficients under seismic excitations are only $23.0 \%$ and $37.5 \%[43,44]$. If TLCDI is installed to mitigate dynamic responses, the reduction coefficients of windinduced acceleration responses of Building 1 and Building 2 are $37.7 \%$ and $42.0 \%$, respectively, while the corresponding reduction coefficients in case of seismic acceleration control 
are only $15.7 \%$ and $26.1 \%[8,48]$. These findings verify that both TMDI and TLCDI are more effective in controlling the wind-induced acceleration responses of adjacent high-rise buildings, as compared to earthquake-induced acceleration responses. Hence, the opposite-sign response factor analyzed in this study could be regarded as an applicable and reasonable indicator to evaluate the mitigation efficiency of passive control devices even prior to their installation.

\section{Data Availability}

The data used to support the findings of this research are available from the corresponding author upon request.

\section{Conflicts of Interest}

The authors declare that they have no conflicts of interest.

\section{Acknowledgments}

This research was supported by Key Laboratory of Structure and Wind Tunnel of Guangdong Higher Education Institutes.

\section{References}

[1] K. Al-Kodmany, "Skyscrapers in the twenty-first century city: a global snapshot," Buildings, vol. 8, no. 12, p. 175, 2018.

[2] G. Hu, K. T. Tse, J. Song, and S. Liang, "Performance of windexcited linked building systems considering the link-induced structural coupling," Engineering Structures, vol. 138, pp. 91104, 2017.

[3] B. Kavyashree, S. Patil, and V. S. Rao, "Review on vibration control in tall buildings: from the perspective of devices and applications," International Journal of Dynamics and Control, pp. 1-16, 2020.

[4] Q. Wang, H. Qiao, W. Li, Y. Yugen, Z. Fan, and N. Deep Tiwari, "Parametric optimization of an inerter-based vibration absorber for wind-induced vibration mitigation of a tall building," Wind and Structures, vol. 31, no. 3, pp. 241-253, 2020.

[5] D.-G. Lee, H.-S. Kim, and H. Ko, "Evaluation of couplingcontrol effect of a sky-bridge for adjacent tall buildings," The Structural Design of Tall and Special Buildings, vol. 21, no. 5, pp. 311-328, 2012.

[6] L.-S. Fur, H. T. Y. Yang, and S. Ankireddi, "Vibration control of tall buildings under seismic and wind loads," Journal of Structural Engineering, vol. 122, no. 8, pp. 948-957, 1996.

[7] C. Christopoulos and M. Montgomery, "Viscoelastic coupling dampers (VCDs) for enhanced wind and seismic performance of high-rise buildings," Earthquake Engineering \& Structural Dynamics, vol. 42, no. 15, pp. 2217-2233, 2013.

[8] Q. Wang, H. Tian, H. Qiao, N. D. Tiwari, and Q. Wang, "Wind-induced vibration control and parametric optimization of connected high-rise buildings with tuned liquid-column-damper-inerter," Engineering Structures, vol. 226, Article ID 111352, 2021.

[9] E. Simiu and D. Yeo, Wind Effects on Structures: Modern Structural Design for Wind, John Wiley \& Sons, Hoboken, NJ, USA, 2019.

[10] W. Kim, Y. Tamura, and A. Yoshida, "Interference effects on local peak pressures between two buildings," Journal of Wind
Engineering and Industrial Aerodynamics, vol. 99, no. 5, pp. 584-600, 2011.

[11] X. F. Yu, Z. N. Xie, X. Wang, and B. Cai, "Interference effects between two high-rise buildings on wind-induced torsion," Journal of Wind Engineering and Industrial Aerodynamics, vol. 159, pp. 123-133, 2016.

[12] X. Yu, Z. Xie, and M. Gu, "Interference effects between two tall buildings with different section sizes on wind-induced acceleration," Journal of Wind Engineering and Industrial Aerodynamics, vol. 182, pp. 16-26, 2018.

[13] H.-S. Kim, "Seismic response control of adjacent buildings coupled by semi-active shared TMD," International Journal of Steel Structures, vol. 16, no. 2, pp. 647-656, 2016.

[14] W. Shen, A. Niyitangamahoro, Z. Feng, and H. Zhu, "Tuned inerter dampers for civil structures subjected to earthquake ground motions: optimum design and seismic performance," Engineering Structures, vol. 198, Article ID 109470, 2019.

[15] S. Mahmoud, "Horizontally connected high-rise buildings under earthquake loadings," Ain Shams Engineering Journal, vol. 10, no. 1, pp. 227-241, 2019.

[16] E. Tubaldi, L. Gioiella, F. Scozzese, L. Ragni, and A. Dall'Asta, "A design method for viscous dampers connecting adjacent structures," Frontiers in Built Environment, vol. 6, p. 25, 2020.

[17] A. Bhaskararao and R. Jangid, "Seismic response of adjacent buildings connected with dampers," in Proceedings of the 13th World Conference on Earthquake Engineering, Vancover, Canada, August 2004.

[18] S.-Y. Ok, "Tuned mass damper asymmetric coupling system for vibration control of adjacent twin buildings," Advances in Structural Engineering, vol. 23, no. 5, pp. 954-968, 2020.

[19] Q. Wang, Z. Li, A. Garg, B. Hazra, and Z.-N. Xie, "Effects of tuned mass damper on correlation of wind-induced responses and combination coefficients of equivalent static wind loads of high-rise buildings," The Structural Design of Tall and Special Buildings, vol. 28, no. 6, p. e1597, 2019.

[20] A. Giaralis and F. Petrini, "Wind-induced vibration mitigation in tall buildings using the tuned mass-damper-inerter," Journal of Structural Engineering, vol. 143, no. 9, Article ID 04017127, 2017.

[21] S. Elias and V. Matsagar, "Wind response control of tall buildings with a tuned mass damper," Journal of Building Engineering, vol. 15, pp. 51-60, 2018.

[22] Q. Wang, S. Yu, C. Ku, and A. Garg, "Combination coefficient of ESWLs of a high-rise building with an elliptical crosssection," Wind and Structures, vol. 31, no. 6, p. 523, 2020.

[23] A. M. Aly and S. Abburu, "On the design of high-rise buildings for multihazard: fundamental differences between wind and earthquake demand," Shock and Vibration, vol. 2015, Article ID 148681, 22 pages, 2015.

[24] A. Vulcano, "Comparative study of the earthquake and wind dynamic responses of base-isolated buildings," Journal of Wind Engineering and Industrial Aerodynamics, vol. 74-76, pp. 751-764, 1998.

[25] X.-J. Hong and M. Gu, "Probability model and solution on earthquake effects combination in along wind resistant design of tall-flexible buildings," Applied Mathematics and Mechanics, vol. 27, no. 5, pp. 627-636, 2006.

[26] D. Duthinh and E. Simiu, "Safety of structures in strong winds and earthquakes: multihazard considerations," Journal of Structural Engineering, vol. 136, no. 3, pp. 330-333, 2010.

[27] H. Mahmoud and G. Cheng, "Framework for lifecycle cost assessment of steel buildings under seismic and wind hazards," Journal of Structural Engineering, vol. 143, no. 3, Article ID 04016186, 2017. 
[28] X.-W. Zheng, H.-N. Li, Y.-B. Yang, G. Li, L.-S. Huo, and Y. Liu, "Damage risk assessment of a high-rise building against multihazard of earthquake and strong wind with recorded data," Engineering Structures, vol. 200, Article ID 109697, 2019.

[29] W. Jing, H. Feng, and X. Cheng, "Dynamic responses of liquid storage tanks caused by wind and earthquake in special environment," Applied Sciences, vol. 9, no. 11, p. 2376, 2019.

[30] Y. Xu, T. Guo, P. Yan, and A. Li, "Effect of semiactive control on wind and seismic responses of high-rise building supported on triple friction pendulums," Journal of Performance of Constructed Facilities, vol. 34, no. 3, Article ID 04020035 , 2020.

[31] T. Roy and V. Matsagar, "Probabilistic assessment of steel buildings installed with passive control devices under multihazard scenario of earthquake and wind," Structural Safety, vol. 85, Article ID 101955, 2020.

[32] L.-Y. Lu, T.-K. Lin, R.-J. Jheng, and H.-H. Wu, “Theoretical and experimental investigation of position-controlled semiactive friction damper for seismic structures," Journal of Sound and Vibration, vol. 412, pp. 184-206, 2018.

[33] Z. Zhang, K. Bi, H. Hao, P. Sheng, L. Feng, and D. Xiao, "Development of a novel deformation-amplified shape memory alloy-friction damper for mitigating seismic responses of RC frame buildings," Engineering Structures, vol. 216, Article ID 110751, 2020.

[34] D. De Domenico, N. Impollonia, and G. Ricciardi, "Seismic retrofitting of confined masonry-RC buildings: the case study of the university hall of residence in Messina, Italy," International Journal, vol. 36, no. 1, pp. 54-85, 2019.

[35] A. Di Matteo, A. Pirrotta, and S. Tumminelli, "Combining TMD and TLCD: analytical and experimental studies," Journal of Wind Engineering and Industrial Aerodynamics, vol. 167, pp. 101-113, 2017.

[36] E. Aydin, "Optimal damper placement based on base moment in steel building frames," Journal of Constructional Steel Research, vol. 79, pp. 216-225, 2012.

[37] E. Aydin, "A simple damper optimization algorithm for both target added damping ratio and interstorey drift ratio," Earthquakes and Structures, vol. 5, no. 1, pp. 83-109, 2013.

[38] D. De Domenico and G. Ricciardi, "Earthquake protection of structures with nonlinear viscous dampers optimized through an energy-based stochastic approach," Engineering Structures, vol. 179, pp. 523-539, 2019.

[39] E. Tubaldi, M. Barbato, and A. Dall'Asta, "Performance-based seismic risk assessment for buildings equipped with linear and nonlinear viscous dampers," Engineering Structures, vol. 78, pp. 90-99, 2014.

[40] Q. Wang, N. D. Tiwari, H. Qiao, and Q. Wang, "Inerter-based tuned liquid column damper for seismic vibration control of a single-degree-of-freedom structure," International Journal of Mechanical Sciences, vol. 184, Article ID 105840, 2020.

[41] D. De Domenico and G. Ricciardi, "Improving the dynamic performance of base-isolated structures via tuned mass damper and inerter devices: a comparative study," Structural Control and Health Monitoring, vol. 25, no. 10, Article ID e2234, 2018.

[42] L. Marian and A. Giaralis, "Optimal design of a novel tuned mass-damper-inerter (TMDI) passive vibration control configuration for stochastically support-excited structural systems," Probabilistic Engineering Mechanics, vol. 38, pp. 156-164, 2014.

[43] D. De Domenico, H. Qiao, Q. Wang, Z. Zhu, and G. Carlo Marano, "Optimal design and seismic performance of Multi-
Tuned Mass Damper Inerter (MTMDI) applied to adjacent high-rise buildings," The Structural Design of Tall and Special Buildings, vol. 29, p. e1781, 2020.

[44] Z. Zhu, W. Lei, Q. Wang, N. Tiwari, and B. Hazra, "Study on wind-induced vibration control of linked high-rise buildings by using TMDI," Journal of Wind Engineering and Industrial Aerodynamics, vol. 205, Article ID 104306, 2020.

[45] GB50009-2012, Load Code for the Design of Building Structures, China Architecture \& Building Press, Beijing, China, 2012.

[46] A. T. Council and U. S. F. E. M. Agency, Quantification of Building Seismic Performance Factors, US Department of Homeland Security, Washington, D. C., USA, 2009.

[47] A. Tributsch and C. Adam, "Evaluation and analytical approximation of Tuned Mass Damper performance in an earthquake environment," Smart Structures and Systems, vol. 10, no. 2, pp. 155-179, 2012.

[48] Q. Wang, H. Qiao, D. De Domenico, Z. Zhu, and Y. Tang, "Seismic response control of adjacent high-rise buildings linked by the tuned liquid column damper-inerter (TLCDI)," Engineering Structures, vol. 223, Article ID 111169, 2020.

[49] Q. Wang, H. Qiao, D. De Domenico, Z. Zhu, and Z.-N. Xie, "Wind-induced response control of high-rise buildings using inerter-based vibration absorbers," Applied Sciences, vol. 9, no. 23, p. 5045, 2019.

[50] J. Dai, Z.-D. Xu, and P.-P. Gai, "Tuned mass-damper-inerter control of wind-induced vibration of flexible structures based on inerter location," Engineering Structures, vol. 199, Article ID 109585, 2019. 